Volume 11, Number $3 \quad 1994$

\title{
ABSTRACTS \\ of
}

Working Papers

in

ECONOMICS

The Official Journal of the AWPE Database

Field Key

$i$

Abstracts of Working Papers in Economics

223

Series Index

299

Keyword Index

309

Permuted Title Index

317

Gaining Access to the AWPE Database

337

CAMBRIDGE

UNIVERSITY PRESS 